Revista Água Viva

\title{
A HISTÓRIA DO OUTRO PARA FALAR DE SI: DA LEITURA À ESCRITA AUTORAL E DE SI POR JOVENS NO ESPAÇO ESCOLAR
}

\author{
THE STORY OF THE OTHER TO TALK ABOUT HIMSELF: FROM READING TO \\ AUTHORIAL AND SELF-WRITING BY YOUNG STUDENTS IN THE SCHOOL \\ SPACE
}

\section{LA HISTORIA DEL OTRO PARA HABLAR DE SÍ: DE LA LECTURA A LA ESCRITURA AUTORAL Y DE SÍ MISMO POR JÓVENES EN EL ESPACIO ESCOLAR}

Gleiser Mateus Ferreira Valério ${ }^{1}$

Recebido em: 30 mar. 2019

Aceito em: 12 jun. 2019

DOI 10.26512/aguaviva.v4i2.23858

RESUMO: A leitura abre espaços, permite encontros, aproxima realidades e é capaz de conduzir o indivíduo por experiências que partem da percepção sensível do mundo para o despertar da criatividade. Pela obra o leitor é capaz, não apenas, de encontrar esse outro presente na narrativa, como de voltar para si, para, assim, ser capaz de relatar sua própria história. Desta premissa inicial, partem os pressupostos do presente artigo, observar a importância da leitura do texto literário para gerar processos de escrita que sejam criativas ou mesmo autorais. Para tal, centramos as análises no projeto Olimpíadas de Língua Portuguesa, criado pelo Ministério da Educação brasileiro e desenvolvido em ambiente escolar por todo o país com intuito de fomentar o interesse por autores da literatura nacional, levando a produções dos estudantes. Mais que apenas focar na reflexão dessas histórias juvenis, publicadas virtualmente em coletâneas, a discussão aqui proposta visa observar os caminhos da leitura literária como parte de um processo cumulativo e intertextual de experimentar o artístico, culminando em possíveis respostas por meio da escrita. Assim, utilizaremos teóricos como Michèle Petit, John Dewey, Mikhail Bakhtin, Michel Foucault e Wolfgang Iser para analisar essa autoria. Por ter o intuito de compreender a narrativa como parte de sua vivência e de si, o gênero memória literária se mostrou fundamental, por se tratar do melhor exemplo da relação entre o estudante e seus pares, seu lugar e os relatos daqueles que construíram (e constroem) sua história.

Palavras-chave: Leitura; Experiência; Autoria; Escrita de si.

\footnotetext{
${ }^{1}$ Doutorando em Literatura pela Universidade de Brasília (PósLIT/UnB) e professor da Educação Básica na Secretaria de Educação do Distrito Federal (SEEDF). Possui graduação em Letras - Língua Portuguesa pela Universidade de Brasília e Mestrado em Literatura pela Universidade de Brasília. E-mail: gleisermateus@hotmail.com
} 


\begin{abstract}
Reading opens spaces, allows encounters, approaches realities and is able to lead the individual through experiences that depart from the sensitive perception of the world to the awakening of creativity. By the work the reader is able, not only, to find this other gift in the narrative, as to return to itself, in order to be able to report its own history. From this initial premise, starting from the assumptions of this article, note the importance of reading the literary text to generate writing processes that are creative or even copyrighted. To this goal, we focus the analyzes on the Portuguese Language Olympics project, created by the Brazilian Ministry of Education and developed in a school environment throughout the country in order to develop interest in authors of the national literature, leading to student productions. More than just focus on the reflection of these juvenile stories, published virtually in collections, the discussion proposed here aims to observe the paths of literary reading as part of a cumulative and intertextual process of experiencing the artistic, culminating in possible responses through writing. Thus, we will use theorists like Michèle Petit, John Dewey, Mikhail Bakhtin, Michel Foucault and Wolfgang Iser to understand this authorship. In order to understand the narrative as part of their experience and of themselves, the genre of literary memory was fundamental because it was the best example of the relationship between the student and his peers, his place and the reports of those who built (and construct) their history.
\end{abstract}

Keywords: Reading. Experience. Authorship. Self-writing.

RESUMEN: La lectura abre espacios, permite los encuentros, acerca realidades y es capaz de conducir al individuo por experiencias que parten de la percepción sensible del mundo para el despertar de la creatividad. Por medio de la obra, el lector es capaz, no sólo, de encontrar el otro presente en la narrativa, como de volver a él mismo, para, así, ser capaz de relatar su propia historia. De esta idea inicial, parten los supuestos del presente artículo: observar la importancia de la lectura del texto literario para generar procesos de escritura que sean creativas o, incluso, actorales. Para eso, centramos los análisis en el proyecto Olimpíadas de Língua Portuguesa, creado por el Ministerio de Educación de Brasil y desarrollado en ambiente escolar por todo el país. Este proyecto tiene el propósito de fomentar el interés por autores de la literatura nacional y las producciones escritas de los estudiantes. Además de reflexionar sobre las historias juveniles, que se publican virtualmente en colecciones, la discusión propuesta en este artículo busca observar los caminos de la lectura literaria como componente de un proceso acumulativo e intertextual de probar lo artístico, culminando en posibles respuestas por medio de la escritura. Así, utilizaremos teóricos como Michèle Petit, John Dewey, Mijaíl Bakhtin, Michel Foucault y Wolfgang Iser para comprender este proceso de autoría. Por percibir la narrativa como parte de su vivencia y de él mismo, el género memoria literaria se mostró fundamental, una vez que ejemplifica de la mejor manera la relación entre el estudiante y sus pares, su lugar y los relatos de aquellos que construyeron (y construyen) historia.

Palabras clave: Lectura. Experiencia. Autoría. Escritura de sí mismo. 


\section{INTRODUÇÃO}

Ao pensar o contexto da literatura, um universo que vai de escritores como Dante Alighieri a Jorge Luis Borges, vários são os livros que relatam experiências pessoais e narrativas de si. Autores que fazem de suas vivências espaços de compartilhamento de suas memórias, sejam elas voltadas para situações que fizeram parte de uma imagem nostálgica e familiar do passado, sejam viagens e contatos com lugares fora de seu cotidiano em momentos específicos. Pela obra, o escritor conta histórias e nos conduz por espaços distantes dos que experimentamos diariamente. Biografias, diários e relatos nos levam a ambientes que talvez, somente por meio da literatura, consigamos atingir ou presenciar. O imaginário do autor, criado na narrativa, entra em contato com o do leitor, por meio da leitura, o que promove a reflexão e a experimentação, algo que pode resultar em processos de escrita, em um diálogo intertextual.

Para se pensar essa realidade marcada por encontros e desencontros com o texto, o presente artigo terá como foco as narrativas de jovens elaboradas em ambiente escolar, tendo como base estratégias pedagógicas que envolvem a leitura e o processo de escrita criativa e autoral. Porém qual a razão para partir da escola os questionamentos da pesquisa em questão? Devemos levar em conta o fato de que crianças e adolescentes com incentivo, ou melhor dizer acesso, à leitura de livros, bem como ao prazer de ler, ainda é associado a uma parcela restrita e elitista da população, pensando o caso do Brasil, de modo que a maior parte das pessoas fica alheia a esse importante elemento cultural, histórico, social e político que é o texto literário. Num contexto cerceante como o de uma parcela vulnerável da população, é em instituições de ensino que muitos estudantes, cotidianamente, tornam-se leitores de obras de escritores renomados para interpretar e debater sobre suas ideias e questionamentos provocados pela literatura, associando-a ao seu cotidiano.

O maior problema, presente na realidade da maioria das salas de aula, parte da falta de aproximação entre o contexto do jovem e o proposto pelo livro, fator este determinante para que o contato com o texto literário se torne um verdadeiro martírio para muitos. Vários são os relatos de escritores reconhecidos no campo literário que descrevem o quão insuportável era a leitura em sala de aula, tal como observa o estudo de Regina Zilberman em A leitura e o ensino de Literatura (2012). Por esta razão, uma das maiores dificuldades docentes é buscar obras que consigam despertar o interesse dos alunos para o ato de ler. O que ainda se percebe é um exercício contínuo de repetições de estratégias retrógradas e massacrantes que tornam as aulas 
um acúmulo de leituras que não provocam o diálogo, encarcera reflexões em propostas de análise prontas e não relacionam com o vivido por eles.

Para uma efetiva prática docente, o professor deve trazer o cotidiano do estudante para o trabalho com a recepção do texto literário. Mais que apenas ler, o aluno contextualiza a obra por meio seus atos íntimos e pessoais, como diria Paulo Freire: "a leitura da palavra não é apenas precedida pela leitura de mundo, mas por uma certa forma de escrevê-lo, quer dizer, de transformá-lo através de nossa prática consciente” (FREIRE, 2011, p. 30). Dos anos que tenho como docente, uma proposta que gerou bons resultados para estabelecer a relação entre o lido e o experimentado são as Olimpíadas de Língua Portuguesa (OLP), projeto promovido pelo MEC em parcerias com instituições de fomento à educação. Por mais que tenha críticas a muitos elementos do concurso, seu material é rico de textos e atividades que podem levar ao prazer da leitura, além de oferecer narrativas que descrevem percepções que fogem ao tradicionalmente analisado pelos estudos literários. Além dos processos de leitura e criação de imaginário, encontramos coletâneas de textos estudantis que não apenas refletem o contato entre aluno e a obra, mas sua capacidade de produzir suas próprias histórias, em um processo de escrita criativa e, porque não dizer, autoral.

Um dos gêneros apresentados é o da memória literária, desenvolvido em turmas de sétimos e oitavos anos do ensino fundamental. Para tal, uma coletânea de textos de escritores como Zélia Gattai, Tatiana Belinky, João Ubaldo Ribeiro e Manoel de Barros, entre outros, são utilizados em sala com a finalidade de levar o jovem a pensar a si e sua realidade, em especial seu contexto de vivência. Com o tema "O lugar onde vivo", o projeto desenvolve uma série de atividades, tendo a literatura como foco de discussão, sobre o lugar, conceito espacial que reflete o afetivo e faz os alunos questionarem seus lócus vividos. O resultado é a produção de narrativas em sala que são selecionadas pelo projeto, nacionalmente, e das quais algumas foram disponibilizadas na página da OLP como coletânea. No caso específico da categoria memória, ela assume um caráter especial, visto o relato não ser propriamente de si, mas de alguém mais antigo na comunidade e que possa descrever o passar dos anos, o desenvolvimento da cidade durante esse tempo. Sendo assim, o estudante deve construir narrativas nas quais assumirá a posição de narrador em primeira pessoa, por meio da história de outrem, tomando essa voz como sua e como parte de si.

Diante dos pontos iniciais levantados, algumas questões ficam latentes e pretendem ser respondidas a partir do presente artigo: Ao elaborar uma narrativa de si, que possíveis representações podem surgir, ainda mais tendo como temática e elemento central o lugar, a 
cidade e o espaço vivido e experimentado pelo jovem? Como analisar essa escrita como autoral e pessoal, partindo de conceitos literários?

Para algumas respostas, tanto as coletâneas de textos literários como as de narrativas dos estudantes servirão como corpus para o artigo. A relação entre a experiência da leitura de memórias dos autores já reconhecidos pelo campo literário e o ato de compor histórias próprias dos jovens será questionada e colocada em xeque para se pensar o que é o escritor e como a escrita pode ser considerada autoral. Com tal finalidade, devemos pensar como essas produções estudantis podem refletir sua base de elaboração, dialogando e tendo uma identidade que não deixa de lado o seu elemento constituidor inicial que é o texto literário. Por fim, observar a infinidade de possibilidades que essas coletâneas são capazes de oferecer para a elaboração de uma escrita de si.

\section{A Leitura do Texto Literário e sua relação com o Imaginário Estudantil}

Ao ler, novos espaços se abrem para as mentes dos indivíduos. O potencial observado nos processos de leitura beira o que denominamos de incalculável. Mais que um ato de prazer, o livro pode se tornar um companheiro diário, aquele que está nos diversos espaços de nossa vivência, a fuga dos males cotidianos, próximo do fugere urbem que os poetas árcades buscavam para atingir a inspiração. Quando nos aproximamos da realidade de jovens estudantes, a necessidade de atividades que promovam o contato obra/leitor não se faz apenas importante, como fundamental. Enquanto seres humanos, somos constituídos e nos construímos a partir de casos e relatos que nos antecedem; desta maneira, fazer da sala de aula o local da narrativa é oferecer a esses alunos oportunidade de conhecer outros (tanto espacial, quanto temporal), dialogar com a tradição e propor sua própria visão de sociedade, tal como afirma Zilberman:

Que a leitura é importante, todos sabemos: a leitura ajuda o indivíduo a se posicionar no mundo, a compreender a si mesmo e à sua circunstância, a ter suas próprias ideias. Mas a leitura da literatura é ainda mais importante: ela colabora para o fortalecimento do imaginário de uma pessoa, e é com a imaginação que solucionamos problemas. Com efeito, resolvem-se dificuldades quando recorremos à criatividade, que, aliada à inteligência, oferece alternativas de ação (ZILBERMAN, 2012, p. 148). 
Mais que apenas uma função contemplativa, a leitura assume a função de despertar a ação para os jovens. Muitas de nossas reflexões em relação à realidade passam por concepções adquiridas a partir do texto literário. Se por um lado alguns questionam tanto a efetividade da Literatura para a sociedade, no espaço escolar, encontramos uma boa resposta para afirmações, por vezes, niilistas em relação ao livro e sua função. Para muitos, principalmente em contextos de alta vulnerabilidade social, as narrativas são fontes inesgotáveis de reflexão e questionamento, posicionando o indivíduo de forma a problematizar a cidadania e a marginalização de determinados grupos em um país. Nesse sentido, atividades como as propostas pela OLP, por mais que centradas em projetos pedagógicos de estrutura governamental, têm extrema viabilidade para promover ações. No caso das coletâneas disponibilizadas, temos outro elemento fundamental: fornecer autores de base nacional, com obras que discutem problemáticas do Brasil e que podem se aproximar do experenciado pelo estudante.

Ao observar a descrição de um jovem que relembra o avô, as brincadeiras de rua com os amigos, ainda crianças, como em $O$ Lavador de Pedra de Manoel de Barros, o leitor entra em contato com esse outro do texto e o aproxima de si. Meninos que corriam como se tivessem comido "canela de cachorro", metáfora tão singela, mas que em muito se conecta com os que constantemente rolam suas bolas pelas ruas de cidades, risos e alegria que contagiam e provocam a memória. Na voz de Barros é que tal situação atinge sua plenitude: Os andarilhos, as crianças e os passarinhos têm o dom de ser poesia. Dom de ser poesia é muito bom! (MEC, 2014, p. 11). Não encontramos aqui os grandes feitos heroicos de mitos universais e sim o trivial do dia a dia, o que não impede que se obtenha a capacidade da construção poética, e isso é muito bom. O lugar - uma cidade pequena, as personagens - crianças e a memória - o avô e a infância são capazes de despertar o lirismo em jovens que se distanciam do experimentado pelo autor no tempo e no espaço.

O contato com essa lembrança faz com que o cotidiano assuma sua importância na temática literária. O leitor encontra no texto elementos de seu dia a dia e gera aproximações, propõe encontros. Se por um lado a obra é capaz de criar mundos novos, em outro ela consegue poetizar o real, como observado em Petit: "Ler não isola do mundo. Ler introduz no mundo de forma diferente. O mais íntimo pode alcançar neste ato o mais universal" (PETIT, 2008, p. 40). Deste modo, o mais geral pode ser universalizado a partir da experiência diária. Os meninos que correm no arruado é uma imagem que pode ser perpetuada em qualquer localidade, sem 
que, com isso, perca seu objetivo proposto quando o escritor optou por essas escolhas para compor a narrativa. Ainda nas palavras sobre leitura de Petit:

Ler permite ao leitor, às vezes, decifrar sua própria experiência. É o texto que "lê" o leitor, de certo modo é ele que o revela; é o texto que sabe muito sobre o leitor, de regiões dele que ele mesmo não saberia nomear. As palavras constituem o leitor, lhe dão um lugar (PETIT, 2008, p. 37).

Muitas vezes, como citado, é, por meio da Literatura que o leitor é capaz de nomear emoções e afetos, palavras são capazes de descrever situações, eventos e oferecer formas de representar realidades, ainda mais em indivíduos em formação. Se histórias permitem identificação, na leitura de Transplante de menina de Tatiana Belinky e Parecida, mas diferente de Zélia Gattai elas fornecem material para que a atividade pedagógica tome novos rumos e sirva de arcabouço para que jovens entrem em contato com seus familiares e conhecidos mais antigos e descubram a constituição de sua comunidade. Na primeira, temos o olhar de uma narradora sobre o primeiro carnaval no Rio de Janeiro, o maravilhar-se com as festividades, os blocos de rua. Mesmo que a compreensão ainda infantil não atinja toda a plenitude do acontecido, permite com que esse olhar para o passado traga um novo mirar para o presente e o futuro. Na segunda, os processos migratórios assumem um caráter central. Italianos são os protagonistas que abandonam suas terras em busca de novas esperanças em um local diferente. As dificuldades, o sofrimento, o abandono são as memórias de tempos que a autora não viveu, mas que consegue transformar em elemento literário para relatar parte de si - a família.

São exemplos como os citados por Zélia Gattai que serviram como mote para o trabalho pedagógico proposto nas oficinas da categoria memória da OLP. Os estudantes não deveriam contar suas experiências, mas procurar pessoas mais velhas que pudessem descrever o passar dos anos no espaço de sua comunidade, para assim, munidos desta história, fossem capazes de construir um novo olhar sobre o lugar, histórico e constitutivo. O contato pelo avô italiano que descreve suas experiências para formar a família é um exemplo para que os jovens transformem as narrativas orais de seus pares em produções originais e que representam lugares com um forte teor emocional e poético, longe da realidade pura, um imaginar sobre experiências que são organizados a partir de camadas que se sobrepõem. A memória coletiva entra em diálogo com a individual, permitindo que o estudante mescle de tal forma as duas, somadas à leitura do texto literário, e crie, em sua própria história, algo novo e que promove o encontro sensível 
entre esses vários mundos experimentados por meio do imaginário. Aproximamos do que teoriza Halbwachs sobre a apropriação do relato do grupo pelo indivíduo:

Para melhor me recordar, eu me volto para eles, adoto momentaneamente seu ponto de vista, entro em seu grupo, do qual continuo a fazer parte, pois sofro ainda seu impulso e encontro em mim muito das ideias e modos de pensar a que não teria chegado sozinho, e através dos quais permaneço em contato com eles (HALBWACHS, 1990, p. 20).

Ao procurar membros mais antigos de uma comunidade, tais como pais, avós, vizinhos e líderes, o estudante aproxima as experiências e os relatos de seus pares com a sua própria vivência, tornando-se parte desse todo que é espacial, social, cultural e histórico. O contato direto com a formação de seu lugar abre portas para que se perceba o poder das narrativas tradicionais de um povo, relacionadas à literatura apresentada na escola. A leitura das memórias em sala, inicialmente, desperta a criticidade e a mente do jovem; o contato com as entrevistas fornece material para que, auxiliado pelo professor, o estudante possa utilizar vários recursos literários para compor narradores e personagens que relatem espaços fora do conhecido pelo campo literário tradicional. Essas produções juvenis abrem nosso horizonte de leitores para cidades, pessoas e situações que, apenas por meio das escolhas desses alunos, atingiremos.

O texto então faz parte de um processo de acumulação de outros que o precedem, como denomina Iser em O fictício e o Imaginário (2013). O jovem, durante a leitura, participa do processo de seleção que é a própria constituição da obra segundo o autor, elemento que transcende o campo do real e do ficcional, elaborado a partir de uma terceira premissa que é o imaginário. O que temos são fragmentos de realidade que se conectam em meio a um ato de fingimento, o que denomina como se, um mundo que é criado e transformado a partir da própria ficcionalidade, da seleção de combinação das várias possibilidades as quais o autor parte para sua composição. Por esta razão, narrativas como as de Gattai, Belinky e Barros se conectam com as concepções do estudante. O imaginário do autor entremeia-se a do estudante, sendo capaz de produzir novas reverberações de processos seletivos, por meio da intertextualidade. Daí questiona-se o fazer literário pela capacidade de duplicar semanticamente os elementos seletivos de modo cumulativo, dialógico, tendo o ato de ler como o de decifrar "um palimpsesto", revelar o algo oculto, contestar algo dado como denomina Iser (2013), ou partindo de suas palavras:

Como os dois tipos de contexto (do livro e do leitor) se atualizam, surge uma coexistência de discursos diferentes, que desenvolvem seus contextos como 
um jogo de mútuo aparecimento e desaparecimento. Daí resulta uma instabilidade semântica que se avoluma porque os discursos reunidos constituem também contextos uns para os outros, de modo a se inserirem em uma relação de tema e horizonte, e movendo-se incessantemente entre si (ISER, 2013, p. 300).

Desta relação que partirá algumas das análises do artigo, a possibilidade da leitura promover a escrita criativa pelos estudantes, originais por sua temática e autorais no âmbito de sua capacidade de transformar sua realidade em narrativas. Claro, por seu caráter de acumulação, a leitura é a base para concepção, relacional e intertextual. Ao ler, o jovem é capaz de se tornar sujeito de sua história, questionar sua participação e relacionar seu cotidiano aos outros que a Literatura lhe ofereceu. Petit assegura que os que leem ficção são "os que têm mais curiosidade pelo mundo real e pelos temas da sociedade" (PETIT, 2013, p. 113). Pelo livro, o leitor permite a abertura de si para o outro, e, assim, consegue representar suas lembranças, ou mesmo a memória advinda de seus familiares e pessoas próximas. Ao utilizar a OLP, o professor permite ao aluno questionar problemáticas sociais individuais e coletivas por meio da voz daqueles que são, na maioria das vezes, silenciados por uma realidade marginalizadora e excludente. De maneira semelhante, podemos compreender essas possibilidades com base no que Petit explana sobre leitura e autoria:

Pela confrontação desses materiais, pistas serão levantadas - que estão longe de esgotar o tema -, para tentar esclarecer a contribuição da leitura em contextos críticos. Tudo começa, como veremos, com situações gratificantes de intersubjetividade, encontros personalizados, uma percepção, uma hospitalidade. A partir daí as leituras abrem para um novo horizonte e tempos de devaneio que permitem a construção de um mundo interior, um espaço psíquico, além de sustentar um processo de autonomização, a construção de uma posição do sujeito. Mas o que a leitura também torna possível é uma narrativa: ler permite iniciar uma atividade de narração e que se estabeleçam vínculos entre os fragmentos de uma história, entre os que participam de um grupo e, às vezes, entre universos culturais. Ainda mais quando essa leitura não provoca um decalque de experiência, mas uma metáfora (PETIT, 2009, p. $15)$.

O que um jovem apreende ao ler Memória de livros de João Ubaldo Ribeiro tem relação direta com sua experiência. No texto, o narrador relata sua infância repleta de livros que o cercavam e que eram capazes de distancia-lo do real e partir para universos imaginários promovidos pela Literatura. O pai, figura fundamental, é um dos grandes motivadores desse "eu" que relata a si e a seu passado, incentivador, mesmo que, por vezes, de maneira autoritária, da leitura. Temos a descrição de um caminho que percorre do ler as primeiras letras, o processo 
de alfabetização, à compreensão de si como leitor. Diferente do narrador de Ribeiro, estudantes de escolas públicas dificilmente possuirão pais que façam leituras em casa de Homero, Camões e Horácio, provavelmente o professor será um dos únicos mediadores que conhecerão. Esses meninos e meninas constituem um país em que o livro é caro e pouco acessível, a cultura letrada ainda é restrita e o contato com a literatura é limitada à escola. Por mais críticas que tenha ao projeto do MEC, tais como a associação com bancos e empresas com interesses que vão além da mera aprendizagem, é inegável sua capacidade de atingir aqueles que estão à margem de uma cultura leitora.

Mais que apenas ter acesso à Literatura, todo o processo pedagógico por trás da OLP permite a escrita de si desses alunos. O próximo passo será estudar as coletâneas de narrativas selecionadas dos estudantes no ano de 2016, último produzido e divulgado virtualmente pelo projeto. Para compreender essa escrita, necessitamos analisar o que é o escritor e como tais textos podem ser entendidos não apenas por sua criatividade, mas por investigarmos sua capacidade autoral. Partimos da relação entre a memória dos escritores citados anteriormente e aquela advinda das histórias orais dos que compõem o cotidiano dos estudantes, para sobreposição de textos que se encontram e dialogam, o que culmina na produção estudantil. Tais narrativas possuem proximidades e distâncias com seus textos literários formadores, as diferenças são elementares para se captar seu teor original, em especial por sua complexidade ao se ter no outro as vicissitudes para a escrita de si.

\section{Autoria, Memória e Escrita de si em narrativas juvenis}

Tendo como base a leitura e o que foi discutido sobre sua importância para o pensamento sobre si, partimos agora para o conceito de autoria e como ele pode ser utilizado para analisar as narrativas contidas nas coletâneas estudantis. Na busca de respostas para os questionamentos propostos, John Dewey apresenta, em A arte como experiência (2010), possíveis chaves para entender os textos juvenis como obras passíveis de uma crítica literária. O teórico conceitua a arte como elemento que requer um posicionamento a partir de sua presença. Mais que apenas uma postura contemplativa, ao estar diante de manifestações artísticas, devemos experimentálas, o que pressupõe uma reação que também pode culminar no ato criativo. A literatura, enquanto arte, não apenas gera um olhar de júbilo, afeição ou conivência, trocas puramente passivas, como permitem ao espectador/leitor sua apropriação, problematizando e manifestando de maneira tal que produza novas narrativas capazes de abarcar uma vasta gama de 
possibilidade, tal como observaremos mais à frente na exploração das memórias literárias dos estudantes. Essas afirmações podem ser observadas no que diz Dewey:

Para perceber, o espectador ou observador tem de criar sua experiência. E a criação deve incluir relações comparáveis às vivenciadas pelo produtor original. Elas não são idênticas, em um sentido literal. Mas tanto naquele que percebe, quanto no artista deve haver uma ordenação dos elementos do conjunto que, em sua forma, embora não nos detalhes, seja idêntica ao processo de organização conscientemente vivenciado pelo criador da obra. Sem um ato de recriação, o objeto não é percebido como uma obra de arte (DEWEY, 2010, p. 137).

Assim, o processo de criação artística envolve o debruçar-se sobre a obra, o que resulta na recriação, algo que não necessita exatidão ao que é inicialmente produzido. Por mais que estudante seja mergulhado no que é dito pelo escritor, suas construções mentais são capazes de extrapolar os limites da obra e criar coisas novas que merecem destaque para nossa análise sobre leitura e escrita. Desta maneira, a Literatura apresenta um caráter dialógico em sua relação com o leitor, sendo que este consegue relacionar o outro apresentado pelo texto literário com suas lembranças e daqueles que o circundam. Além disso, podemos questionar todo o processo acumulativo anteriormente citado e a obra como parte de um processo polifônico e intertextual, tal como preceitua Bakhtin:

A obra, como a réplica do diálogo, está disposta para a resposta do outro (dos outros), para a sua ativa compreensão responsiva, que pode assumir diferentes formas: influência educativa sobre os leitores, sobre suas convicções, respostas críticas, influência sobre os seguidores e continuadores; ela determina as posições responsivas dos outros nas complexas condições de comunicação discursiva de um dado campo da cultura. A obra é um elo na cadeia da comunicação discursiva; como a réplica do diálogo, está vinculada com outras obras - enunciados: com aquelas às quais ela responde, e com aquelas que lhe respondem; ao mesmo tempo, à semelhança da réplica do diálogo, ela está separada daqueles limites absolutos da alternância dos sujeitos do discurso (BAKHTIN, 2003, p. 279).

O leitor, nessa perspectiva, possui uma posição responsiva diante da obra, o que possibilita atos como o da escrita. A narrativa é parte de um conjunto de outras que a precederam e, como tal, situa-se numa relação intrínseca com as várias vozes que a formaram. O autor então é leitor de outros que o antecederam, seus livros são parte de um campo, no caso o literário, um todo situado temporal e espacialmente para além de apenas sua escrita. Tais concepções Bakhtiniana e de Dewey dialogam com a Foucaultiana de hypomnemata. Em O que 
é o autor (1992), o teórico argumenta sobre esses textos que serviam de base para meditações, análises e conexão com a memória, necessários para as produções que surgiam ligadas a eles. O objetivo não era de cópia, mas de criar a partir desses elementos constitutivos do pensamento. Estas são as bases que temos questionado como elementares para a formação do escritor, ligadas diretamente à tradição que o precedeu, apropriando-se dela em novas narrações, tal como declara Foucault:

\begin{abstract}
O papel da escrita é constituir, com tudo o que a leitura constituiu, um "corpo" (quicquid lectione collectum est, stills redigat in corpus). E, este corpo, há que entende-lo não como um corpo de doutrina, mas sim - de acordo com a metáfora tantas vezes evocada da digestão - como o próprio corpo daquele que, ao transcrever as suas leituras, se apossou delas e fez sua a respectiva verdade: a escrita transforma a coisa vista ou ouvida "em forças e em sangue" (in vires, in sanguinem). Ela transforma-se, no próprio escritor, num princípio de acção racional (FOUCAULT, 1992, p. 133).
\end{abstract}

Ainda que não possua uma perspectiva teórica, mas um caráter de relato pessoal, Alberto Manguel, em Uma história da Leitura (2004), analisa os contatos com o texto literário em sua vida e que levaram à autoria. Várias são as obras e os escritores citados e que serviram de peças para compor sua criatividade e sua individualidade. A importância de ler e do prazer que o ato causa é abordado sobre vários vieses, numa mescla das experiências próprias de Manguel e de suas pesquisas sobre os caminhos que levaram autores ao seu processo composicional. No capítulo intitulado A leitura ouvida, temos a descrição da importância da figura do lector, aquele que recitava poemas e lia histórias para os outros de maneira oral, algo que perpassa desde a cultura grega, os monges beneditinos, a Europa moderna, aos enroladores de fumo cubano. Por mais que sejam apresentados os lados positivos e negativos dessa leitura coletiva, cabe destacar sua importância para tornar o cotidiano e o trabalho árduo diário algo prazeroso e cercado de aventuras para os que se punham a ouvir os relatos.

As perspectivas de Manguel dialogam com a relação teórica estipulada anteriormente baseada em Dewey, Bakhtin e Foucault pelo fato de ser um exemplo prático dos encontros e desencontros que a leitura promove para que gere a escrita. O percurso histórico-literário percorrido por Manguel é comparável, em uma escala menor, ao promovido pela OLP nessa busca de encontrar os pontos convergentes e divergentes entre a obra, o leitor e o ato criativo. A imersão pelas várias possibilidades de descrição desse ato de leitura é uma chave para se pensar o contato com o artístico de maneira a experimentar, ter uma postura responsiva e criar a partir do lido, em contato direto com o imaginário. 
O relato dos charuteiros cubanos que se envolviam com os livros oralmente narrados, enquanto enrolavam as folhas de fumo, uma mistura de prazer e labor que culminava no produto final, ou seja, o charuto, pode ser analisado, de maneira metafórica, com o processo leituraescrita aqui proposto. Os estudantes entram em contato com o texto literário constante nas coletâneas, tornam-se leitores e acessam um novo espaço que é a memória do autor. Ao entrevistarem o membro de sua comunidade, imergem em outras narrativas que são parte de seu espaço vivido, mas também integrantes fundamentais de si e de suas experiências cotidianas. No momento em que levam as entrevistas para a escola e iniciam a produção de seus próprios textos, o contato entre o artístico e o relatado toma forma, não como algo externo, memória coletiva apenas, e, sim, como parte da escrita de si. As camadas de leitura vão se sobrepondo, tomando forma, adquirindo sentido e especificidade, assim como as folhas do fumo que se grudam e se transformam em algo que está para além de sua constituição natural.

Pelas leituras dos autores da Literatura brasileira contemporânea encontrados nas coletâneas trabalhadas em aula pelos professores durante a OLP, os jovens procuram indivíduos que possam relatar a formação da cidade e de seu surgimento para que, assim, possam se assumir como autores das memórias de seu lugar. Apropriam-se não apenas das obras literárias, como de todo uma história oralizada de seu povo. Experimentam o objeto artístico em sua plenitude, agem de maneira responsiva e acumulativa diante da leitura e dos discursos que o precedem e digerem esse "corpo", apossam-se das memórias e criam algo original. Os relatos que constituem as narrativas estudantis podem ser interpretados por meio das definições de Ricoeur (2007) sobre a memória individual e coletiva. Ao trazer a fala de seus familiares e sua comunidade, pensamos nesse outro que nos é próximo, o qual, mesmo não sendo parte de nossas lembranças pessoais, dialoga com nossa constituição como indivíduos. Podemos aproximar da tríplice atribuição da memória - o si, o outrem e o próximo, como denomina o teórico: "meus próximos são aqueles que me aprovam por existir e cuja existência aprovo na reciprocidade e na igualdade da estima" (RICOEUR, 2007, p. 142).

Como a temática do projeto é "O lugar onde vivo", a afetividade se constitui não apenas a partir da lembrança, mas da ligação direta com o espaço e o vivenciado. Essa relação é observada em Memórias inundadas no passado em que conhecemos a realidade de Itá - SC, cidade presente apenas no passado e no âmbito da memória por hoje se encontrar no fundo de uma represa. As casas, as ruas, as infâncias foram tomadas pelo choro e pela água, elementos simbólicos do progresso que atinge a região, impossibilitando até o olhar contemplativo para o lugar que foi parte da constituição dos seres que ali se criaram. Na fala do próprio narrador, 
marcada pela nostalgia e pela dor da perda: "Itá, onde eu estiver, estarei contigo, inundado pela saudade que tu me deixaste" (MEC, 2016, p. 71). O que, nas coletâneas de autores consagrados, mantinha um voltar-se para o passado para relatar as experiências vividas, nos textos dos alunos adquire um teor social forte, fruto de uma realidade marcada por questões como os processos de desenvolvimento e como eles afetam a natureza e a vida das pessoas. As falas desses narradores dialogam com o define Assman sobre o espaço como recordação:

[...] um local dotado de aura não traz promessa de algo imediato; mais que isso, é um local em que se podem perceber sensorialmente o afastamento e distância irrecuperável do passado. O local da recordação é de fato uma "tessitura incomum do espaço tempo", que entretece presença e ausência, o presente sensorial e o passado histórico. Se a marca da autenticidade é a ligação entre o aqui e o agora, então o local da recordação, como aqui sem um agora, não passa de autenticidade parcial. Longe de unir as duas metades, o local da recordação insiste em mantê-las separadas como aqui e outrora (ASSMAN, 2011, p. 360).

Da mesma forma que a narrativa citada, encontramos tais traços em Desengavetando memórias em que observamos a degradação do local e o desenvolvimento que chega à cidade de Catalão - GO de maneira negativa e relegando as alegrias do passado ao campo da memória. Na maioria das histórias, percebemos o progresso e a imagem do que ficou para trás como perdido no tempo, e no espaço, todo um conjunto de elementos que não estão mais ali e que provocam a nostalgia. Ao forçar a mente, lembramos, provocamos o retorno do vivido para o presente, tornamos o experenciado em real, aproximando da definição de Ricoeur: "Porém, o que é lembrar-se? É ter uma imagem do passado. Como isso é possível? Porque essa imagem é um vestígio deixado pelos acontecimentos que permanece fixado na mente" (RICOEUR, 2010, p. 22).

O lugar é assumido como memória e parte integrante dos indivíduos, seus passados e o experimentado junto aos seus. Tamanha a relação estabelecida que, mesmo em estudantes diferentes e de locais distintos, esse olhar para a mudança do tempo e do espaço se aproxima, como a imagem das linhas do trem, o avançar tecnológico e como ele influencia na transformação da cidade. Nas narrativas Ferrovia da Saudade e Sobre galhos, correntes $e$ vagões, encontramos o passado de lugares tão distantes, a primeira passada na Bahia e a segunda em Ceará, mas que constroem imageticamente a formação de um povo às margens das linhas do trem e como, com a tecnologia e o crescimento, este meio tão importante vai perdendo sua funcionalidade. Se por um lado não serve mais como meio de transporte e condução pelo 
espaço, assume sua relevância nas lembranças, por ser um relato vivo, esquecido enquanto funcionalidade, mas ativo na memória dos que permanecem. Relacionamos, novamente, ao que afirma Assman:

\begin{abstract}
Mesmo quando os locais não têm em si uma memória imanente, ainda assim fazem parte da construção de espaços culturais da recordação muito significativos. E não apenas porque solidificam e validam a recordação, na medida em que a ancoram no chão, mas também por corporificarem uma continuidade da duração que supera a recordação relativamente breve de indivíduos, épocas e também culturas, que está concretizada em artefatos (ASSMAN, 2011, p. 348).
\end{abstract}

Acreditamos que este rememorar atinge um de seus pontos chaves em Gotas de Alegria. A narradora Francisca de Assis descreve o seu passado no interior do Amazonas, a alegria pueril advinda das chuvas que caem, elemento diário para quem conhece a realidade da região de floresta brasileira. O que chama atenção é a descoberta, ao final do texto, de sua cegueira. $\mathrm{O}$ que temos é a memória do lugar construída puramente no sentimento, no nostálgico, no pensamento. A escuridão da vida, tomada pela perda de um dos sentidos que tanto nos constitui enquanto humanos, perde seu tom negativo nas gostas de chuva que caem sobre o corpo já idoso, trazendo o espaço para o campo de uma realidade, tomando vida e formato e abandonando a invalidez. Nas palavras, cita Casimiro de Abreu, a lembrança do tão repetido verso sobre a "aurora da vida", longe da dura situação de decrepitude que o envelhecer traz. Aliás, aqui observamos uma constante dos textos que é o valor de citar autores e escritores de seu passado, tais como: Patativa do Assaré, José de Alencar, Graciliano Ramos, entre outros, concretizando toda a discussão sobre a leitura como formadora do imaginário e das novas formas de expressar suas lembranças sobre o lugar.

\title{
CONSIDERAÇÕES FINAIS
}

As discussões propostas reforçam então alguns pontos fundamentais: a leitura e sua capacidade de acumulação e construção das narrativas, e os livros e autores como parte de um conjunto de elementos necessários para que o leitor seja capaz de produzir suas próprias narrativas. Tais produções, além de originais, podemos denominar como autorais, por serem parte de uma relação intertextual e de resposta ao proposto pela posição ativa perante o objeto artístico. Assim, um projeto como a OLP, inicialmente criado com a finalidade de promover a leitura e melhorar a capacidade de estudantes na escrita de textos em norma padrão, bem como 
a compreensão de diferentes gêneros textuais, é capaz de extrapolar suas premissas centrais e apresentarem materiais que permitem outras análises para além de seu objetivo inicial. Nas falas presentes na produção desses jovens, observamos tais questões:

Hoje desenrolei fios do novelo de minha vida. Consegui voltar à vila e revisitar, com vocês, momentos de puro encantamento e já sou professor, estou me sentindo um escritor. A grande obra? A minha infância. O cenário? Um paraíso no lugar onde vivemos. Os expectadores? Nós. O preço? Muitas emoções. (MEC, 2016, p. 107).

Tamanha é a vontade de falar, e mesmo de ser ouvido, que o próprio narrador em $D e$ volta ao Paraíso, presente no trecho citado, constrói um verdadeiro ensaio sobre os elementos constitutivos da narrativa e de como se insere como autor, o que representa uma amálgama de toda a argumentação desenvolvida no presente artigo. Assim como o ato de ler não pode ser controlado ou preso em amarras, o resultado que ele causa na imaginação do leitor transcende a prática pedagógica. Pouco se questiona ou interpreta essas coletâneas de textos juvenis, ficam expostas como um prêmio para os selecionados na página do concurso, mas representam algo muito além disso, são escritas de si, do outro, do próximo, construções sobre o passado, memórias acumuladas que oferecem a nós, pesquisadores, denominações particulares e pouco acessíveis pelo campo literário sobre diversos lugares e pessoas. No relatar dessas cidades, espaços e vozes marginalizadas por uma dominação das regiões metropolitanas tomam forma e são passíveis de exploração.

\section{REFERÊNCIAS}

ASSMAN, Aleida. Espaços de recordações: formas e transformações da memória cultural. Tradução de Paulo Soethe. Campinas: Unicamp, 2011.

BAKHTIN, Mikhail. Estética da criação verbal. Tradução de Paulo Bezerra. 4 ed. São Paulo: Martins Fontes, 2003.

DEWEY, John. A arte como experiência. São Paulo: Martins Fontes, 2010.

FREIRE, Paulo. A importância do ato de ler: em três artigos que se completam. 51 ed. São Paulo: Cortez, 2011.

FOUCAULT, Michel. A escrita de si. In: O que é um autor? Lisboa: Passagens. 1992. p. 129160. 
HALBWACHS, Maurice. A memória coletiva. Tradução de Laurent Léon Schaffter. São Paulo : Vértice, 1990.

ISER, Wolfgang. O fictício e o imaginário: perspectivas de uma antropologia literária. Tradução de Johannes Kretschmer. 2 ed. Rio de Janeiro: EdUERJ, 2013.

MANGUEL, Alberto. Uma história da leitura. Tradução de Pedro Maria Soares. São Paulo: Companhia das Letras, 2004.

MEC. Coletânea: memórias literárias. São Paulo: Cenpec (coleção das Olimpíadas de Língua Portuguesa), 2014.

MEC. Textos finalistas. São Paulo: Ministério da Educação, 2016.

PETIT, Michèle. Os jovens e a leitura: uma nova perspectiva. Tradução de Olga de Souza. São Paulo: Editor 34, 2008.

PETIT, Michèle. A arte de ler ou como resistir à diversidade. Tradução de Olga de Souza. São Paulo: Editora 34, 2009.

PETIT, Michèle. Leituras: do espaço íntimo ao espaço público. Tradução de Olga de Souza. São Paulo: Editor 34, 2013.

RICOEUR, Paul. A memória, a história, o esquecimento. Tradução de Alain François [et al.] Campinas: Editora da Unicamp, 2007.

RICOEUR, Paul. Tempo e narrativa - a intriga e a narrativa histórica. Tradução de Claudia Berliner. São Paulo: Martins Fontes, 2010.

ZILBERMAN, Regina. A leitura e o ensino de literatura. Curitiba: Intersaberes, 2012. 